\title{
INOVAÇÕES CURRICULARES PARA FORMAÇÃO EM SAÚDE INSPIRADAS NA OBRA DE ANÍSIO TEIXEIRA
}

\section{SYLLABUS INNOVATIONS FOR HEALTH EDUCATION INSPIRED BY ANISIOTEIXEIRA'S WORK}

\author{
Naomar de Almeida-Filho ${ }^{1}$ iD (0000-0002-4435-755X), Tânia Celeste Matos Nunes² iD (0000-0001-5631-5085)
}

\author{
${ }^{1}$ Universidade Federal da Bahia, Instituto de Saúde Coletiva, Salvador, Bahia, Brasil. \\ ${ }^{2}$ Fundação Oswaldo Cruz, Vice Presidência de Educação, Comunicação e Informação, Rio de Janeiro, Rio \\ de Janeiro, Brasil. < tcnunes@globo.com>
}

Resumo Este artigo teve o objetivo de compartilhar questões e reflexões provocadas pelo desafio de organizar o projeto curricular, em regime de ciclos, dos cursos de saúde da Universidade Federal do Sul da Bahia. Inspirado no sistema universitário norte-americano, que tem os colleges como nível inicial de formação, o primeiro ciclo dos cursos de saúde da instituição compõe-se de um bacharelado interdisciplinar em saúde, com duração de três anos, e uma proposta de formação docente para o ensino médio com foco na promoção da saúde, qualidade de vida e educação inclusiva, ainda em fase preliminar de elaboração, o que reforça a integração da universidade no sistema geral de educação. A inspiração da obra e vida de Anísio Teixeira se revela em dois planos: em seu projeto de uma universidade popular e no conceito de escola democrática, incorporada como efeito prático no modelo de Escola Parque, especialmente nos temas da educação integral, inclusiva e fundada em práticas concretas. Em relação aos processos de ensino-aprendizagem presentes na obra anisiana, o artigo destaca a valorização de pedagogias críticas fundadas na capacidade de 'aprender fazendo' e o papel da ciência e da tecnologia como distintivo cultural da modernidade.

Palavras-chave bacharelado interdisciplinar; escola democrática; Anísio Teixeira; ensino em saúde; formação em saúde.
Abstract This text aimed to share questions and reflections provoked by the challenge of organizing the syllabus project, in cycle regime, of the health courses of the universidade Federal do Sul da Bahia. Inspired by the American University system, which has colleges as the initial level of training, the first cycle of the health course is composed of an Interdisciplinary Bachelor in Health, lasting three years, and a proposal for training teachers for high school with a focus on Health Promotion, Quality of Life and Inclusive Education, still in preliminary phase of elaboration, reinforcing the integration of the university into the general system of education. The inspiration is the work and life of Anísio Teixeira, which reveals itself in two planes: in his project of a Popular University and in the concept of the democratic school, incorporated as a practical effect in the model of Escola Parque, especially in the themes of integral, inclusive education, founded on concrete practices. Regarding the teaching-learning processes present in the Anisian work, the text highlights the value of critical pedagogies founded on the ability to 'learn by doing' and the role of science and technology as a cultural distinctive of modernity.

Keywords interdisciplinary undergraduation; democratic school; Anísio Teixeira; teaching in health; formation in health. 


\section{Introdução}

Os autores clássicos do campo da saúde coletiva (Arouca, 1975; Donnangelo, 1976) já priorizavam a questão da educação, tanto no âmbito da formação profissional quanto no da organização social e política dos serviços de saúde. Entretanto, na realidade concreta do Brasil contemporâneo, temas de educação e formação não vêm sendo considerados como necessários e até cruciais para impactar positivamente a situação social de saúde (Almeida-Filho, 2014). No plano geral do sistema de ensino, a problemática da saúde e qualidade de vida infelizmente tem se constituído em grande e profunda lacuna, especialmente na educação básica, o que dificulta a difusão e a consolidação de uma cultura de promoção da saúde.

Do ponto de vista normativo, parâmetros curriculares nacionais já estabelecem a saúde como tema transversal a ser didaticamente trabalhado de forma interdisciplinar na educação básica. Para tanto, a escola deve ter uma visão holística do ser humano, bem como contar com professores com formação interdisciplinar e de referência na área da educação em saúde. De fato, a escola representa um espaço privilegiado para fomentar autonomia, participação crítica e criatividade essenciais para a promoção da saúde. Nessa perspectiva, o Programa Saúde na Escola (PSE), ação integrada dos ministérios da Saúde e da Educação (Brasil, 2007a), proposto na perspectiva de ampliar as ações específicas de saúde aos alunos da rede pública de ensino do Brasil, compreende as seguintes áreas: avaliação clínica e psicossocial dos escolares; ações de segurança alimentar e promoção da alimentação saudável; promoção das práticas corporais e atividade física nas escolas; educação para a saúde sexual, saúde reprodutiva e prevenção das infecções sexualmente transmissíveis (ISTs)/aids; prevenção ao uso de álcool e tabaco e outras drogas; promoção da cultura de paz e prevenção das violências; promoção da saúde ambiental e desenvolvimento sustentável.

No que se refere à intersetorialidade no campo da saúde, mais especificamente no ambiente escolar, a atuação docente deve se dar de maneira colaborativa com as equipes de saúde da família, dividindo a responsabilidade sobre a situação de saúde de seu território. Assim, para o desenvolvimento do trabalho interdisciplinar em saúde na escola, nos moldes propostos pelas diretrizes curriculares nacionais (DCNs) para a educação básica (Brasil, 2015), é urgente uma revisão crítica dos processos educativos e formativos desenvolvidos pelas instituições de ensino superior. Requer-se, portanto, cuidadosa e profunda reflexão sobre as DCNs para os cursos de graduação em saúde (Brasil, 2013), incluindo a discussão e a implementação de propostas inovadoras.

Contudo, na prática, a questão da saúde na escola tem se resumido a ações pontuais, disciplinares e com baixa qualidade pedagógica. $\mathrm{O}$ tema transversal saúde é pouco trabalhado na educação básica, devido, entre outros fatores, 
ao despreparo do professor e à concepção equivocada, ainda presente nos educadores, de restringir a concepção de saúde a doenças e a noções elementares de higiene (Fernandes, Rocha e Brasilino de Souza, 2005; Brasil, 2007a; Brasil, 2007b; Opas, 2007; Silva, 2010). A falta de formação pedagógica de grande parte dos profissionais da saúde também parece ser um fator limitante de ações interdisciplinares e pedagogicamente referenciadas de promoção da saúde (Silva et al., 2014).

Com a mudança de conjuntura mundial no fim do século $\mathrm{XX}$, resultando na organização de sistemas públicos de saúde em vários países desenvolvidos, amplia-se a cobertura de serviços e, em consequência, a necessidade de atenção primária de saúde em escala massiva. No Brasil, no plano específico da educação em saúde, essa tendência tem produzido enorme pressão sobre o sistema formal de ensino, originalmente organizado de modo disciplinar, com base em faculdades tradicionais e estágios hospitalares orientados para a crescente especialização (Almeida-Filho, 2011). Dessa forma, avanços políticos no setor, que permitiram a criação do Sistema Único de Saúde (SUS), não têm sido suficientes para aprimorar os modelos de formação profissional vigentes na realidade brasileira atual.

O perfil predominante do egresso do ensino superior em saúde no Brasil, uma década e meia após o estabelecimento das diretrizes curriculares gerais das profissões de saúde, ainda segue um padrão conservador, a ser criticado e superado (Almeida-Filho, 2011). Vários corolários caracterizam tal sistema. Primeiramente, a dura competição para o ingresso nos cursos de elevado prestígio social (por exemplo, medicina), geralmente após cursos preparatórios caros, transforma aquelas carreiras em verdadeiros monopólios das elites, cujos membros tendem a reproduzir como modelo de atuação abordagens individualistas e privadas relativamente aos cuidados de saúde. Em segundo lugar, currículos fechados, projetados para exclusividade na formação, tendem a ser menos interdisciplinares e mais especializados, alienando assim segmentos profissionais entre si e dificultando um eficiente trabalho em equipe. Em terceiro lugar, quase não há lugar no referencial crítico da saúde coletiva para os estudos mais gerais, necessários para promover uma ampla visão humanista das doenças e dos cuidados de saúde pelos profissionais de saúde.

Na prática, os sujeitos formados nesse modelo revelam-se desconhecedores (quando não antagonistas) do SUS, principal política estratégica de Estado para a superação da dívida social da saúde para com a imensa maioria da população brasileira. Em particular, na educação médica, o modelo de formação ainda predominante entre nós, na melhor das hipóteses, treina técnicos competentes, porém em pouca medida comprometidos com as políticas públicas de cuidado em saúde. Os egressos das escolas médicas brasileiras, em sua maioria, mostram-se carentes de uma visão crítica da sociedade e da 
saúde, com atitude pouco humanística e distanciada dos valores de promoção da saúde, revelando, por tudo isso, escasso sentimento de solidariedade e empatia com o sofrimento social.

O vetor da formação, sem dúvida, é importante para a reprodução da crise da saúde, porém não cobre o essencial dessa problemática. A dissonância entre missão política do SUS e processos concretos do sistema de ensino superior pode ser tomada como resultante de grave crise na reprodução do campo da saúde em nosso país (Almeida-Filho, 2011). Daí a falência de tantas reformas curriculares, na medida em que as políticas públicas de saúde não têm sido suficientemente potentes para transformar o mercado de trabalho e o sistema assistencial, em paralelo com a hegemonia de modelos de educação fundados sobre pedagogias de fragmentação e ausências, sem lugar para concepções integradoras do processo saúde-enfermidade-cuidado.

Este artigo teve o objetivo simples e singelo de compartilhar questões e reflexões provocadas pelo desafio de organizar, de modo consistente e rigoroso, o projeto curricular dos cursos de saúde da Universidade Federal do Sul da Bahia (UFSB), articulado a programas de formação de carreiras e profissões de saúde numa perspectiva aberta e emancipadora. Tal desafio compreende a busca por modelos de formação de sujeitos críticos capazes de implementar políticas públicas em saúde, operar práticas resolutivas de cuidados em saúde e produzir conhecimento relevante para a saúde da população, com equidade, justiça e qualidade. Nesse percurso, sem dúvida a inspiração da obra e vida de Anísio Teixeira se revela em dois planos: por um lado, em seu projeto de uma universidade popular; por outro, no conceito de escola democrática, incorporada como efeito prático no modelo de Escola Parque. Além da implantação de um modelo curricular em regime de ciclos que, no plano específico, a experiência da UFSB configura-se como um bacharelado interdisciplinar em saúde, procurou-se reforçar a integração da universidade no sistema geral de educação, resultando num modelo de licenciaturas interdisciplinares nos principais campos de conhecimento, incluindo uma proposta de formação docente para o ensino médio com foco na promoção da saúde, qualidade de vida e educação inclusiva.

\section{Anísio Teixeira e a universidade popular}

Anísio Spínola Teixeira (1900-1971), intelectual inquieto, notável construtor institucional, líder político, foi um dos esteios da fase áurea do desenvolvimentismo, ocupando-se, ao longo da década de 1950, do requisito fundamental para o desenvolvimento nacional, que é a educação. Ele tinha uma clara visão política do tema: além de basal para processos de desenvolvimento econômico, a educação deve ser entendida fundamentalmente como processo emancipatório - anos antes, escrevera Anísio que a escola é a máquina de fazer democracia. 
Anísio nasceu em Caetité, interior da Bahia. Ainda jovem, recém-graduado em direito, foi convidado a ocupar um cargo que hoje equivaleria a secretário de educação do estado da Bahia. Revelou-se então exímio gestor público e, em menos de três anos, conseguiu garantir acesso pleno ao ensino básico em Salvador (Viana Filho, 2008). O sucesso foi tão notável que quando Pedro Ernesto liderou, no Rio de Janeiro, uma experiência democrática em pleno contexto de endurecimento do governo Vargas rumo ao Estado Novo, foi por ele convidado para o cargo de diretor de instrução do então Distrito Federal. Após superar o conjunto de problemas do que hoje chamamos de ensino básico, Anísio lançou o projeto da Universidade do Distrito Federal, envolvendo os maiores intelectuais do Brasil, por ele convidados a pensar uma universidade de vanguarda de nível mundial, mas que nunca perdesse a 'alma brasileira' (Teixeira, 1998).

A curta história de tão revolucionário projeto configura mais uma dessas tragédias brasileiras. A Ditadura Vargas e a Igreja Católica viam sua aliança conservadora ameaçada pelas ideias de Anísio. Os jesuítas, que dominavam o cenário brasileiro da educação superior, fizeram oposição cerrada ao jovem educador. A direita católica iniciou uma forte campanha de difamação, denunciando-o como infiel, demoníaco e, mais que tudo, comunista. Com ordem de prisão decretada, Anísio se refugiou em Caetité. O Governo Vargas fez uma intervenção na Universidade do Distrito Federal, nomeando Alceu Amoroso Lima como reitor, com a finalidade explícita de desmontá-la como experimento institucional (Mendonça, 2002).

Após a redemocratização, em 1946, Anísio foi convidado a trabalhar na Organização das Nações Unidas para a Educação, a Ciência e a Cultura (Unesco), em Nova Iorque. Depois de cumprir sua tarefa, com saudades do Brasil, aceitou o convite de Octávio Mangabeira para o cargo de secretário de educação da Bahia. Esse é o momento mais frutífero da trajetória de Anísio, pois representa ocasião de colocar em prática várias de suas ideias, com financiamento suficiente e forte apoio político. É dessa época o conceito da Escola Parque, assim como a criação da primeira Fundação Estadual de Apoio à Pesquisa (Viana Filho, 2008).

Reintegrado ao serviço público federal em 1950, Anísio passou a trabalhar no Ministério da Educação e Cultura, onde, com seu parceiro Rômulo Almeida (1914-1988), fundou a Coordenação de Aperfeiçoamento de Pessoal de Nível Superior (Capes), hoje um dos principais órgãos financiadores da formação acadêmica no Brasil. Mentor e colaborador de Anísio, Rômulo Almeida o introduziu na vanguarda acadêmica dos então nascentes campos do planejamento e da gestão. Nessa fase, é importante destacar também a relação de Anísio com o jovem antropólogo e escritor Darcy Ribeiro (1922-1997), que daria importante contribuição, pouco mais tarde, ao processo de criação da Universidade de Brasília. 
Nessa época, ápice do projeto político desenvolvimentista de construir Brasília como a cidade vanguarda do mundo, o presidente Juscelino Kubitschek encomendou a seus auxiliares um projeto de universidade que seria também a mais avançada do mundo. Baseado no Instituto Nacional de Estudos Pedagógicos (Inep), que ele fundara e do qual era também diretor-geral, Anísio já realizava no Ministério da Educação e Cultura um conjunto de atividades realmente de grande fôlego. Ao ser convocado, convidou Darcy Ribeiro, então seu discípulo e colaborador, o qual aproveitaria a oportunidade para se firmar como uma das lideranças de mais rápida ascensão naquele momento político. Os dois desenharam um projeto de universidade que recupera o ideário da Universidade do Distrito Federal, vanguarda na década de 1930, e o atualiza incluindo uma série de ideias que Anísio havia desenvolvido entre 1954 e 1958, em vários textos publicados na Revista Brasileira de Estudos Pedagógicos do Inep.

A proposta de criação da Universidade de Brasília (UnB), ilustrada por um magistral plano arquitetônico criado por Lúcio Costa e Oscar Niemeyer, foi tão valorizada que Juscelino fez dela tema da mensagem presidencial no dia do aniversário da nova capital, em 21 de abril de 1960, encaminhando ao Congresso Nacional o respectivo projeto de lei, tendo Anísio Teixeira como presidente da Comissão de Elaboração e Darcy Ribeiro como seu relator. Durante o curto período do governo Jânio Quadros, o projeto ficou engavetado; sua votação e aprovação foram tumultuadas. Darcy conseguiu retirá-lo do fundo de uma gaveta e o colocou no pacote de projetos que iriam à votação em bloco no dia da renúncia de Jânio, com o Congresso mergulhado numa tremenda confusão (Ribeiro, 1995).

Anísio Teixeira tinha sessenta anos no momento em que se implantou a UnB. Darcy fora nomeado reitor e Anísio, vice; mas Darcy tinha assumido a chefia da Casa Civil de João Goulart, de modo que Anísio foi, de fato, o primeiro reitor. A UnB nasceu com um desenho revolucionário, pois propunha uma estrutura inovadora, organizada em institutos de ciências básicas e centros de formação, superando o modelo bonapartista de faculdades e grandes escolas isoladas. Na prática, essa formulação implicava dois anos de formação geral, mais um ano para completar um bacharelado, que era terminal, pré-requisito para acesso à graduação profissional. Esse modelo lembra muito o sistema universitário norte-americano, que tem o college como nível inicial de formação. Sabemos que Anísio teve uma formação muito importante nos Estados Unidos. Mas também Isaías Alves e outros grandes educadores brasileiros tentaram, em vários momentos, adaptar aos trópicos o modelo do college (Almeida-Filho, 2014).

O modelo de ciclos concebido por Anísio chegou a ser implantado na Universidade de Brasília, porém o projeto como um todo sofreu forte reação política contrária. Essa resistência dirigiu-se contra todos os projetos de 
reforma de base do governo João Goulart, inclusive modelos avançados de educação (como a pedagogia contextual de Paulo Freire). Não obstante, sob a liderança de Anísio e o apoio político de Darcy, a UnB, ao se organizar tendo a pesquisa científica e a ação cultural como referência institucional, tornou-se uma 'meca acadêmica' no Brasil. Cientistas, ilustres professores e intelectuais progressistas acorreram a Brasília.

O principal movimento de tropas no Distrito Federal por ocasião do golpe militar de 1964 foi a invasão e ocupação da Universidade de Brasília, narrada em detalhes por um dos seus fundadores, o físico Roberto Salmeron, num livro marcante intitulado A universidade interrompida (Salmeron, 2008). Anísio Teixeira foi exonerado, processado e aposentado compulsoriamente, mas sem direito a pensão ou outra prerrogativa. Aconselhados por Anísio, docentes e dirigentes resolveram ficar para resistir. A universidade continuou funcionando por mais algum tempo, uma vez que o primeiro reitor interventor, Zeferino Vaz, terminaria aceitando o modelo curricular inicialmente proposto e passou a colaborar com as inovações acadêmicas, até ser demitido pelos militares, junto com alguns professores. Nesse momento, outubro de 1965, a maioria dos professores se demitiu em protesto e a UnB praticamente encerrou suas atividades. Uma sucessão de reitores interventores, com destaque para o militar José Carlos de Azevedo, assumiu a condução do desmonte da utopia anisiana, que culminaria, recentemente, com a restauração do modelo de faculdades e a refragmentação dos cursos. ${ }^{1}$

O conceito de universidade popular foi concebido por Anísio no final da década de 1940, após o seu retorno de Nova York. Segundo a original concepção anisiana, a universidade é a única instituição social capaz de promover a recriação contínua da cultura. Para ele, cultura significava o conjunto de atividades realizada pelo homem, em sociedade. Essa atribuição da universidade envolve uma tomada de partido, ao integrá-la na vida da sociedade, sem qualquer espécie de paternalismo, e ao exercitar um extenso e profundo olhar crítico sobre o mundo que a cerca (Rocha, 2002).

O projeto de uma universidade popular radical tinha como principal elemento a introdução do regime de ciclos e o conceito de colégio universitário. A reforma universitária proposta por Anísio também já previa cursos de formação geral semelhantes aos bacharelados interdisciplinares como uma possibilidade de acesso universal à educação universitária. Além disso, indicava, sem hesitação, que as trajetórias de seleção para carreiras profissionais ou acadêmicas implicariam opções por um mesmo ciclo de formação com a 'introdução da formação acadêmica ao lado e independente da profissional'. Em várias oportunidades, Anísio demonstrava o maior respeito pela qualidade e atualidade da formação médica realizada no Brasil na primeira metade do século XX. Chegou a afirmar que "nas escolas de medicina estaria o modelo para a implantação da universidade moderna no Brasil" (Teixeira, 2005, 
p. 79). Não obstante seu respeito e admiração pelo rigor científico que atribuía à escola médica do seu tempo, Anísio Teixeira também se posicionava fortemente contra o perfil profissionalizante e estreito da universidade brasileira, submetida ao jugo das corporações.

Além disso, ele enfatizava dois aspectos cruciais para a questão da educação superior no campo da saúde: o caráter público da universidade e o papel central da autonomia na educação superior. Em relação ao primeiro ponto, Anísio foi premonitório também na identificação dos problemas estruturais da universidade brasileira que levaram a um processo de expansão desenfreada, à base da grande ampliação do setor privado, incentivada pela política educacional da década de 1990. No que concerne à questão da autonomia, Anísio lamentava o fato de o mundo inteiro ter avançado numa determinada direção (modelo humboldtiano e depois flexneriano), enquanto a universidade brasileira teria conservado um sistema superado (o modelo bonapartista). ${ }^{2}$

\section{Anísio Teixeira e a educação básica: experiência da Escola Parque}

Ao visar à educação emancipadora 'para todos e não apenas para alguns', Anísio Teixeira sempre reafirmava sua posição política de educador comprometido com a igualdade, viabilizada, na prática, pelo uso intensivo das então incipientes tecnologias educacionais (Viana Filho, 2008). Ao fazê-lo, antecipava o contexto atual de valorização das metodologias ativas de aprendizagem mediadas por tecnologias de informação e comunicação. Em diferentes momentos, sua prolífica obra sintetiza elementos de definição conceitual importantes para sua proposta, a um só tempo revolucionária e pragmática, da escola democrática, tornada realidade no projeto da Escola Parque de Salvador e do Plano de Educação do Distrito Federal.

A experiência da Escola Parque na Bahia se desenvolveu de forma intensa entre 1954 e 1961, conduzida por um grupo de gestores educacionais e professores primários (denominação da época) amparados nas ideias anisianas de integrar estudantes e suas famílias a um processo educativo de preparação para a vida. Conforme o próprio Anísio Teixeira (1969, p. 15), “o projeto da Escola inspirou-se na teoria da Educação pela experiência, envolvendo estrutura completamente nova da Escola, nova organização das classes, dos programas, do currículo e do método de ensino". Para ele, esse foi um esforço de organização dos alunos com base em suas próprias experiências, "visando assegurar não somente uma vida rica e feliz, como um crescimento em inteligência, em capacidade executiva e em convivência humana de alta complexidade social" (Teixeira, 1969, p. 15).

A proposta compreendia um complexo, com a Escola Parque e três Escolas Classe, situadas em bairros populares e de grande população concentrada, com famílias de baixo poder aquisitivo. No complexo de educação integral, conviviam estabelecimentos vinculados ao governo estadual e ao governo federal. 
Os alunos circulavam por dentro desse complexo, em tempo integral, para cumprir atividades curriculares intra e extraclasse, com intensa participação de estudantes, professores e dirigentes na organização curricular e na projeção das atividades que constituíam o dia a dia da inovação pedagógica. As escolas contavam com bibliotecas e também com um setor artístico e recreativo. As crianças faziam refeições na escola, com alimentos das hortas cultivadas pelos próprios alunos. Os estudantes contavam ainda com a assistência de um serviço social, serviço médico e serviço dentário. Um ônibus da escola dava retaguarda às atividades extramuros, com visitas às comunidades, passeios, visitas a museus e outras áreas públicas e de estudos (Jatobá, 2018, entrevista).

A Escola Parque era uma escola experimental de nível primário (hoje correspondente ao Ensino Fundamental), que tinha por objetivo a demonstração de métodos de educação e ensino, servindo como campo de observação e experimentação para professores bolsistas, que ali faziam cursos de aperfeiçoamento. Exercia atividades de coordenação e de renovação permanente das pautas e programas. $\mathrm{O}$ ensino adaptava-se aos alunos, com maior atenção às diferenças individuais. Nesse modelo, a educação era interpretada como porta de entrada para o mundo real, em que os estudos deveriam constituir uma base sólida para futuras opções de carreiras e participação dos estudantes em atividades de exposição ao trabalho, num momento de expressivas mudanças nas relações sociais e econômicas no Brasil. O contexto de transformação e complexificação das cidades (que passavam por um processo de crescimento acelerado, onde conviviam o moderno e o urbano) desafiava principalmente famílias em condições de maior vulnerabilidade social.

O movimento impulsionado por Anísio Teixeira se inseria em um campo de discussão que se constituiu de forma mais organizada no Brasil a partir dos anos 20, conhecido como 'escolanovismo', que passou a influenciar o imaginário das escolas, reproduzindo práticas e propagando-se com ação política para influenciar a organização da escola pública brasileira em torno da visão de uma escola alegre e renovada. Alguns pressupostos orientaram essa experiência como: “a centralidade da criança nas relações de aprendizagem, o respeito às normas higiênicas na disciplinarização do corpo do aluno e de seus gestos, a cientificidade da escolarização de saberes e de fazeres sociais e a exaltação do ato de observar e de intuir, na construção do conhecimento do aluno" (Vidal, 2000, p. 497). Para a autora, esses enunciados já integravam prescrições dos relatórios de inspetores e de preceitos legais no final do século XIX, mas foram ressignificados pelo escolanovismo nas práticas escolares, na década de 1920 como 'novas' questões. Deslocado do 'ouvir' para o 'ver', agora o ensino associava 'ver' a 'fazer' . (Vidal, 2000, p. 498). No 'escolanovismo', houve grande revalorização das bibliotecas escolares, inclusive subsidiando o trabalho dentro da sala de aula. "O bom funcionamento das bibliotecas demandava também a aquisição de livros" (Vidal, 2000, p. 507) e 
estimulava o debate entre alunos, mediante as pesquisas realizadas dentro da sala de aula; também os eventos dedicados ao livro foram disseminados nas escolas. Mas a concepção renovada de educação de Anísio Teixeira e as práticas por ele orientadas para a experiência da Escola Parque transcenderam as recomendações do escolanovismo, resultando num projeto mais amplo e criativo, que reunia arte com ciência, vivências práticas do cotidiano da cidade, simulando situações que permeavam o seu aprendizado em ambientes controlados como bancos, mercados, padarias, armazéns, correio, museus, jornal, cinema, jardim zoológico, livrarias, lojas, atividades agrícolas, música. Havia frequentemente simulação de processos eleitorais tendo os alunos como atores principais e protagonistas da ação concreta que incorporavam a materialidade da vida em comunidade. Visitas a espaços culturais da cidade eram frequentes, assim como a produção de materiais e produtos por meio do núcleo de organização das práticas. A cidade dos estudos e das práticas tinha salas de aula que se transformavam em palcos, onde, por exemplo, a limpeza pública possibilitava estudos e práticas sobre a coleta de lixo e a mobilidade urbana era oportunidade para se estudar a territorialidade social (Éboli, 1969).

Os currículos se desenvolviam por projetos, integrando os saberes recomendados na educação formal às experiências cotidianas dos alunos inseridos em experiências práticas da cidade, tomada como referência concreta nas atividades da escola. A relação professor/aluno experimentou processos de redução das assimetrias; por meio de exercícios de caráter democrático, os estudantes podiam se manifestar com cartas enviadas no Correio da Cidade da Escola e outras formas de reivindicação, muitas delas absorvidas pela gestão da escola.

A experiência da Escola Parque foi guiada pelos seguintes princípios, destacados por Éboli (1969, p. 25 e 26):

1. Ter no centro a criança, baseando seu trabalho no propósito de aprender do aluno e não em planos impostos, alheios às suas experiências infantis;

2. Ter currículo constituído de atividades e não por matérias de ensino;

3. Escolher essas atividades de acordo com interesses e objetivos da criança e dirigi-las tendo em vista sua futura participação na comunidade;

4. Estar integrada na vida real, relacionando suas experiências às experiências do lar e meio social;

5. Ter por objetivo como resultados dessas atividades: a educação integral do aluno, seu crescimento sob os vários aspectos, de sua personalidade e de acordo com suas possibilidades; sua integração na comunidade; sua eficiência no processo do refazer, reconstruir e melhorar a vida;

6. Empenho do professor - estimular o querer aprender em contraposição à domesticação da Escola Tradicional que se organiza em matérias.

Além disso, a Escola Parque permitiu experimentar saberes que eram considerados essenciais a uma escola engajada na experimentação de prá- 
ticas pedagógico-políticas consoantes com os papéis atribuídos por Anísio Teixeira à educação e ao papel da escola para aquele tempo. A gama de aquisições infantis em saberes, hábitos e atitudes procurou enlaçar o processo de ensino-aprendizagem com atividades humanas, integrando a formação a um processo emancipatório das crianças e famílias vinculadas às atividades do projeto (Éboli, 1969).

A experiência do complexo Escola Parque e Escolas Classe, sob a coordenação da professora Carmen Teixeira, irmã de Anísio, durou seis anos. Esse momento de inovação demanda um registro cuidadoso e analítico que deve ser destacado e difundido, instigando a se pensar nos papéis atribuídos à escola no mundo contemporâneo, com a perda substancial de seu caráter emancipatório e de participação na organização de práticas sociais, tão presentes na experiência aqui comentada e conduzida por professores da época. A recuperação dessa história revela o sucesso de uma ex-aluna que superou suas dificuldades e se tornou professora de inglês em um colégio de Salvador, foi tomada como símbolo de esperança pelos professores da 'escola diferente', depositária da expectativa de um novo amanhã e que poderá "comunicar à sociedade a mensagem da experiência de sua classe, para a edificação de todos nós, igualmente culpados da iniquidade de nossa sociedade" (Teixeira 1969, p. 19).

Vale mencionar as palavras de Anísio Teixeira no prefácio do livro de Éboli sobre a 'escola diferente', quando se refere ao êxito da experiência, advertindo que

a modéstia e o silêncio com que se processou essa experiência entre 1956 e 1961, no isolamento de um bairro periférico de Salvador na Bahia, não devem impedir de ver nela mais que uma experiência pedagógica. O fato de ter se realizado em um meio extremamente pobre, com crianças que seriam consideradas marginais pelos padrões ordinários de julgamento, dá à experiência um valor muito mais amplo, não só em relação às potencialidades da educação, como em relação às possibilidades do desenvolvimento social brasileiro (Teixeira,1969, p. 18).

Para Anísio, ainda nesse prefácio, “a nota verdadeiramente triste do relato está na última parte onde estão contempladas as referências aos ex-alunos" (Teixeira, 1969, p. 19). O desabafo que integra o prefácio assinado por ele expressa a perplexidade com o relato das situações dos 62 alunos localizados e entrevistados, dos quais 36 não conseguiram continuar seus estudos (Éboli, 1969, p. 233). Também Anísio (Teixeira, 1969, p. 19) comentou:

[...] vê-se aí com clareza meridiana a trágica ironia da renovação educacional, sem a renovação da sociedade. A experiência escolar termina. A sociedade não acolhe as crianças, que deixam a escola com nenhum quadro organizado de trabalho e emprego ou de continuação da educação. 


\section{Formação em saúde na Universidade Anisiana}

Recentemente, profunda transformação ocorreu no cenário da educação superior no Brasil. Aproveitando programas de expansão como o Plano de Expansão e Reestruturação das Universidades Federais (Reuni), várias universidades públicas iniciaram oferta de formação superior em regime de ciclos. Nesse contexto, emergiu o modelo implantado na Universidade Federal da Bahia a partir de 2009 - que, na época, foi chamado de Universidade Nova (Almeida-Filho, 2007) -, depois retomado e aperfeiçoado na Universidade Federal do Sul da Bahia (UFSB) como Universidade Anisiana (Almeida-Filho, Benincá e Coutinho, 2017). O projeto político-pedagógico da UFSB funda-se em três aspectos: primeiro, arquitetura curricular organizada em ciclos de formação; segundo, regime letivo quadrimestral, com otimização de equipamentos, instalações, pessoal e recursos financeiros; por último, uma combinação de pluralismo pedagógico e uso intensivo de tecnologias digitais de ensino-aprendizagem.

O ingresso de alunos se dá em cursos de primeiro ciclo, de duas maneiras: em bacharelados interdisciplinares (BIs) e em licenciaturas interdisciplinares (LIs), por meio de seleção geral com o Exame Nacional do Ensino Médio (Enem); em licenciaturas interdisciplinares, na Rede Anísio Teixeira de Colégios Universitários. Colégios universitários compreendem unidades acadêmicas descentralizadas, implantadas em localidades com mais de 20 mil habitantes e mais de trezentos egressos do Ensino Médio. Funcionam preferencialmente em turno noturno, em instalações da rede estadual de Ensino Médio, oferecendo programas metapresenciais de educação superior. Cada ponto da rede conta com um pacote de equipamentos de tele-educação de última geração, conectados a uma rede digital de alta velocidade.

O primeiro ciclo é oferecido em quatro grandes áreas: artes, humanidades, ciências e saúde. Trata-se de cursos de três anos com diplomação plena, que podem servir como pré-requisito para formação profissional de graduação ou diretamente para formação científica ou artística de pós-graduação. A estrutura interna do BI compreende duas etapas: formação geral e formação específica. Na etapa de formação geral, esse modelo de educação universitária compreende uma estrutura curricular aberta e flexível: línguas modernas (minimamente português e inglês), informática instrumental (letramento digital e competências conectivas), pensamento lógico-interpretativo (uso eficiente de estratégias analíticas e retóricas) e cidadania planetária (consciência ecológico-histórica).

A interdisciplinaridade que define essa modalidade de bacharelados é promovida de modo difuso em sua estrutura curricular aberta ou diretamente, por indução de componentes optativos. O subeixo interdisciplinar do BI, dessa forma, define-se pela exposição induzida ao que chamamos de cultu- 
ras da contemporaneidade: cultura humanística, cultura artística e cultura científica. Se o aluno entra no BI de artes, tem que cursar dois componentes curriculares livres em ciências e dois em humanidades; se entra no BI de humanidades, tem que fazer dois componentes em artes e dois em ciências; no caso, os alunos dos BIs de ciências ou de saúde devem incorporar dois componentes em artes e dois em humanidades.

Nessa fase inicial, apenas dois blocos de componentes são obrigatórios: língua portuguesa e estudos da contemporaneidade. Língua portuguesa, poder e diversidade cultural é o primeiro módulo do subeixo linguagens, ofertado a todos os alunos do BI. O segundo módulo compreende leitura e produção de textos em língua portuguesa. $\mathrm{O}$ terceiro módulo desse eixo assume o formato de uma oficina de textos acadêmicos e técnicos em saúde. O subeixo estudos da contemporaneidade trata de questões essenciais para o entendimento da posição da pessoa no mundo, como por exemplo ambiente, culturas e sociedades; política, instituições e organizações; ética, indivíduo e subjetividade; história dos saberes: foco na universidade.

Ainda na formação geral, inicia-se o eixo prático-cognitivo com componentes curriculares essenciais de orientação profissional. Como ilustração, coloca-se em destaque o BI-saúde (Almeida-Filho et al., 2014). Nesse caso, trata-se de um componente de introdução ao campo da saúde, incluindo história do campo, apresentação de saberes e práticas de saúde, métodos de pesquisa, formação profissional, visão panorâmica da área, regulação das práticas profissionais. Caso assim o deseje, o aluno do BI poderá cursar módulos similares das outras grandes áreas que servirão como orientação profissional alternativa, propiciando oportunidades de transição vocacional.

Na etapa de formação específica, há possibilidade de a formação nas linguagens ser completada com língua estrangeira. Nessa fase, começam os módulos curriculares da grande área: racionalidades em saúde, bases morfofuncionais etc., mas note-se que muito da estrutura curricular permanece de livre escolha. O eixo de formação técnico-científica prossegue com os seminários interdisciplinares de pesquisa em saúde e - o que consideramos importantíssimo - incorpora um subeixo de linguagem matemática aplicada à formação em saúde. No último ano do BI, o eixo prático-cognitivo se amplia, o de formação técnico-científica prossegue e, em todos os eixos, predominam módulos livres. A essa altura, ao cursar essa estrutura típica, o(a) estudante poderá tomar como opção uma área de concentração, completando os módulos livres com componentes curriculares que fazem parte dos programas de formação profissional a serem cursados posteriormente no segundo ciclo.

O conceito de área de concentração implica que os componentes sejam fundamentalmente optativos, de maneira que uma parte dos alunos faz alguns componentes, outra parte cursa outros módulos, antecipando elementos curriculares do processo da formação profissional desejada. Aqui já se pode 
cursar as estruturas gerais da formação clínica, na lógica dos componentes curriculares amplos e multifuncionais, já que muitos desses módulos podem ser incorporados ao próprio BI. Alguns componentes do segundo ciclo são específicos da formação profissional, como por exemplo estágios curriculares na atenção primária em saúde, não podendo ser objeto de antecipação nas áreas de concentração (Figura 1).

Formação profissional em saúde no regime de ciclos

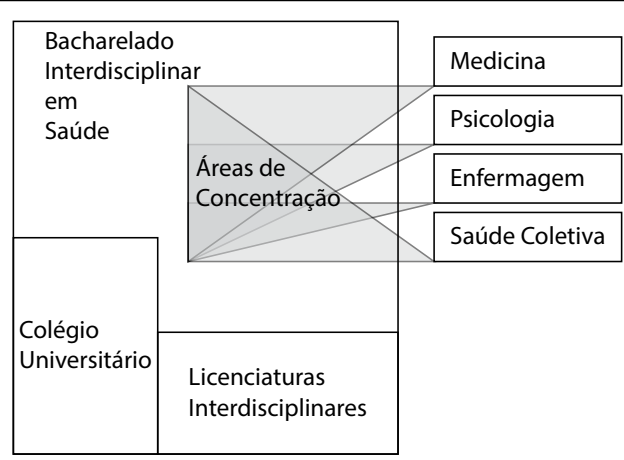

Fonte: Universidade Federal do Sul da Bahia, 2017.

Após conclusão do BI-saúde, o estudante pode prosseguir para o curso de medicina, tendo que cursar no mínimo mais quatro anos de formação eminentemente prática, em equipes de aprendizagem ativa (Almeida-Filho et al., 2015). Caso não preencha os requisitos e critérios de progressão para sua escolha principal no segundo ciclo de formação, o aluno conclui seu curso de primeiro ciclo e receber o diploma de bacharel em saúde; também migrar para outras formações profissionais em saúde, com a vantagem de que as mudanças de percurso não acrescentam tempo à formação profissional porque muitos eixos, módulos e componentes são comuns, ou ainda se inscrever em processos seletivos para cursos de terceiro ciclo. Portanto, o egresso pode prosseguir diretamente para mestrados na área das ciências da saúde, como saúde coletiva, patologia e biotecnologia, por exemplo, e daí para o doutorado.

Durante todo o segundo ciclo do curso médico da UFSB, aqui tomado como exemplo, os alunos deverão frequentar oficinas de cuidado à saúde baseado em evidências, nas quais se estimulam uma análise crítica de artigos científicos e uma discussão aprofundada, com os docentes, da abrangência das novas publicações e sua aplicabilidade naquela comunidade e no cotidiano da prática médica ( $\mathrm{Al}$ meida-Filho et al., 2015). Também devem ser cursados pelos estudantes, durante todo o segundo ciclo, quatro componentes optativos e quatro componentes 
livres, interagindo com os demais cursos da saúde. Os alunos também deverão realizar atividades complementares, participando de atividades de pesquisa e extensão, encontros, congressos e simpósios, entre outras.

No segundo ciclo de formação em saúde, são oferecidos componentes curriculares relacionados ao eixo ético-político-humanístico, atualizando a discussão das políticas de saúde no Brasil, com foco em questões relacionadas à gestão pública e aos programas do SUS e uma constante preocupação com a formação de um profissional participativo, analítico e capaz de interagir com os diversos setores sociais e políticos na resolução dos problemas de saúde. Por um lado, isso implica aprofundamento no estudo das relações interpessoais no cuidado à saúde, explorando as interfaces com a psicologia e com a ética, discutindo os alicerces e o impacto das relações com o indivíduo, a comunidade e a equipe de trabalho, na busca de melhor qualidade de vida para si e para o outro. Por outro lado, o estudante deverá construir uma percepção crítica das relações sociais no exercício da sua prática de ação tecnológica. Numa vertente, isso se dará pela discussão da atuação profissional como forma de modificar o meio onde se vive, suas atitudes em relação ao ambiente, à cultura e à sociedade. Em outra vertente, enfatiza-se uma compreensão política e social do mundo como um sistema complexo interligado em que todos são corresponsáveis pela vida e pelo ambiente.

\section{Formação em saúde, qualidade de vida e educação inclusiva}

Recentemente, foi elaborado projeto complementar para uma licenciatura interdisciplinar em saúde, qualidade de vida e educação inclusiva (LI-saúde) na UFSB, que infelizmente não entrou no processo deliberativo da instituição. A proposta compreende uma formação interdisciplinar de base artística, científica e humanística, voltada à formação de professores da educação básica habilitados às práticas de promoção da saúde, atividade física e educação inclusiva, mediante a imersão em atividades e vivências que constituem o dia a dia docente (UFSB, 2017).

Egressos da LI-saúde terão formação plena para docência no ensino básico, numa perspectiva transdisciplinar e intercultural. Deverão atuar em componentes curriculares interdisciplinares e, especificamente, componentes ligados à educação em saúde, com ênfase em práticas corporais e educação inclusiva. Estarão capacitados a operar recursos multifuncionais atendendo estudantes com deficiência, por meio do ensino colaborativo, apoiando os professores e colaborando com eles em sua atuação com os estudantes com deficiência, na elaboração e implementação de projetos de consultoria colaborativa educacional visando à ampliação da escolarização dos estudantes com deficiência. Busca-se formar um professor com autonomia profissional, autor e pesquisador de sua própria prática, que se reconhece como sujeito em processo de formação permanente. 
A formação desse novo profissional se dará mediante seis etapas formativas, organizadas em formação geral, formação pedagógica, formação específica, formação em Componentes Curriculares (CC) optativos, formação em CCs práticos e formação em CCs livres. Na matriz curricular, encontram-se discriminadas as metodologias específicas de construção do conhecimento em diferentes componentes curriculares, em vez de formações disciplinares conteudistas. A lista de componentes curriculares pode ser visualizada no Quadro 1. A LI-saúde possui simetrias na formação específica com o BI-saúde e na formação pedagógica com as demais LIs por meio do núcleo comum de educação, garantindo assim a eficiência e a otimização dos recursos operacionais, didáticos e humanos.

Quadro 1

Componentes curriculares da licenciatura interdisciplinar-Saúde na Universidade FSB.

Componentes curriculares de formação específica

Campo da saúde: saberes e práticas*

Promoção da saúde, sustentabilidade e qualidade de vida

Políticas e serviços de saúde

Educação popular em saúde

Educação e comunicação em saúde

Seminário integrado em práticas em saúde, atividade física e educação inclusiva

Análise de situação de saúde

Práticas integradas de promoção e vigilância em saúde em espaços de convivência

Desenvolvimento humano e ciclo vital

Bases ecológicas em saúde

Sistemas de controle homeostáticos e alostáticos

Bases morfofuncionais da saúde humana

Saúde na escola: avaliação clínica e psicossocial

Saúde na escola: promoção da atividade física e alimentação saudável

Saúde na escola: educação sexual e prevenção ao uso de drogas

Saúde na escola: promoção da paz e da saúde ambiental

Esporte, saúde e sociedade

Atividade física e saúde

Práticas corporais populares: jogos, brinquedos e brincadeiras

Práticas corporais populares: esportes, danças e lutas

Atividade física adaptada

Corporeidade, subjetividade e contemporaneidade

Modos de brincar, modos de cantar, modos de contar, modos de aprender

Acessibilidade, inclusão e saúde

Intervenções pedagógicas e necessidades educacionais especiais 


\section{Quadro 1}

Componentes curriculares da licenciatura interdisciplinar-Saúde na Universidade FSB.

CCs de formação optativa

Saúde da família e da comunidade

Introdução à pesquisa em saúde

Neurociências e comportamento

Concepção e formação

Biologia celular

Bioquímica

Bioética

Estatística básica

Gênero, sexualidades e saúde

Semiologia/propedêutica clínica geral

Semiologia/propedêutica dos problemas de saúde na infância e adolescência

Estudos sobre corpo e movimento expressivo: observação e investigação

Ateliê em corpos tempos espaços

Corporalidades negrodescendentes no Brasil

Lazer, educação e saúde

Interdisciplinaridade: teoria e método

Laboratório interdisciplinar e intercultural: educação para as diferenças

Laboratório interdisciplinar e intercultural: pedagogias ativas

Laboratório interdisciplinar e intercultural: planejamento e avaliação

Laboratório interdisciplinar e intercultural: análise de material didático

Laboratório interdisciplinar e intercultural: aspecto do desenvolvimento humano

Componentes curriculares práticos

Práticas corporais e saúde na escola: diagnóstico

Práticas corporais e saúde na escola: planejamento

Práticas corporais e saúde na escola: atuação

Práticas corporais e saúde na escola: avaliação

Além dos CCs específicos das áreas de saúde e dos CCs livres, que podem ser cursados em qualquer área, o estudante deverá participar de atividades complementares, aqui compreendidas como atividades artísticas, culturais, esportivas, científicas e de representação estudantil na universidade, na comunidade, em instituições, organizações ou outros espaços, visando à aquisição ou produção de conhecimentos e habilidades importantes para o exercício profissional, o voluntariado e a cidadania, e que contribuam para uma enriquecida complementação da sua formação pessoal, social, cultural e acadêmica. Para completar as horas previstas para atividades complementares, o estudante deverá participar de atividades variadas, não podendo preencher toda a carga horária/creditação com um único tipo de atividade.

Essas atividades contemplam as seguintes dimensões: humana - desenvolvimento social, cultural e pessoal do(a) estudante, ampliando sua consciência 
reflexiva e cidadã; social - empreendedorismo socialmente referenciado, atividades comunitárias, trabalho voluntário na comunidade, em associações de bairros e na universidade; profissional - atividades que enriqueçam a formação técnico-profissional requeridas pelo curso, área de formação ou área complementar; acadêmica - atividades científicas, filosóficas, artísticas, culturais ou esportivas que consolidam a formação integral universitária em complemento à formação específica; política estudantil - atividades que envolvam o estudante em temáticas de interesse coletivo relacionadas à representação formal em entidades estudantis e conselhos, comissões ou congêneres da universidade.

Nos complexos integrados de educação (CIEs) - uma das instâncias da UFSB para a qual convergem seus ciclos de formação e que é formada por atores que acolhem e participam das equipes de aprendizagem ativa (EAAs) - emerge a possibilidade de se vivenciar e participar efetivamente de práticas voltadas à educação integral em tempo integral no período diurno e à educação integral no período noturno (Almeida-Filho, Benincá e Coutinho, 2017). Nesse momento específico, trata-se da oportunidade de vivenciar uma escola em processo de transformação e mudança, com todas as implicações políticas e pedagógicas. Os CIEs tornam-se campo privilegiado para as práticas voltadas principalmente à interdisciplinaridade, à metodologia de projetos, aos métodos ativos, encontro de saberes, vivência de diferentes espaços tempos na escola, cidade educadora, comunidades de aprendizagem, elaboração de material didático, avaliação processual, planejamento participativo, trabalho coletivo e em equipes, currículo, gestão participativa, e que necessitam da colaboração de estudantes e docentes da UFSB. Para desenvolver atividades nos/com os CIEs, o estágio supervisionado deve buscar a parceria com outras redes de ensino e outras escolas, incluindo escolas do campo, indígenas, quilombolas, iniciativas não formais, e ampliar sua área de atuação com respeito aos processos próprios de cada rede, associação, movimento ou instituição.

Além das estratégias próprias da primeira etapa de formação geral, os CCs da formação específica são organizados com foco em duas estratégias pedagógicas específicas: por um lado, coelaboração de conhecimentos, competências, habilidades e capacidades em equipes de aprendizagem ativa; por outro, compartilhamento da vivência pedagógica mediante corresponsabilização dos(as) estudantes em processos de ensino-aprendizagem. Um elemento essencial dessa proposta consiste no desenvolvimento de ações em parcerias, internas e externas, operadas em diferentes níveis institucionais com base em espaços de diversidade. Tais espaços devem ser criados por grupos de cursos, engajados em ações integradas em ambientes produtivos, dentro da própria instituição, em espaços educativos formais, informais e não formais ou em trabalhos de campo. Os espaços de diversidade são constituídos e ocupados por turmas de diversos cursos, grupos e períodos, engajadas em ações integrativas (Almeida-Filho et al., 2015). 
Tais estratégias articulam-se num sistema integrado de aprendizagem compartilhada. Esse modelo constitui um sistema integrado de supervisão-preceptoria-tutoria-monitoria, demonstrado na Figura 2.

Figura 2

Sistema integrado de aprendizagem compartilhada

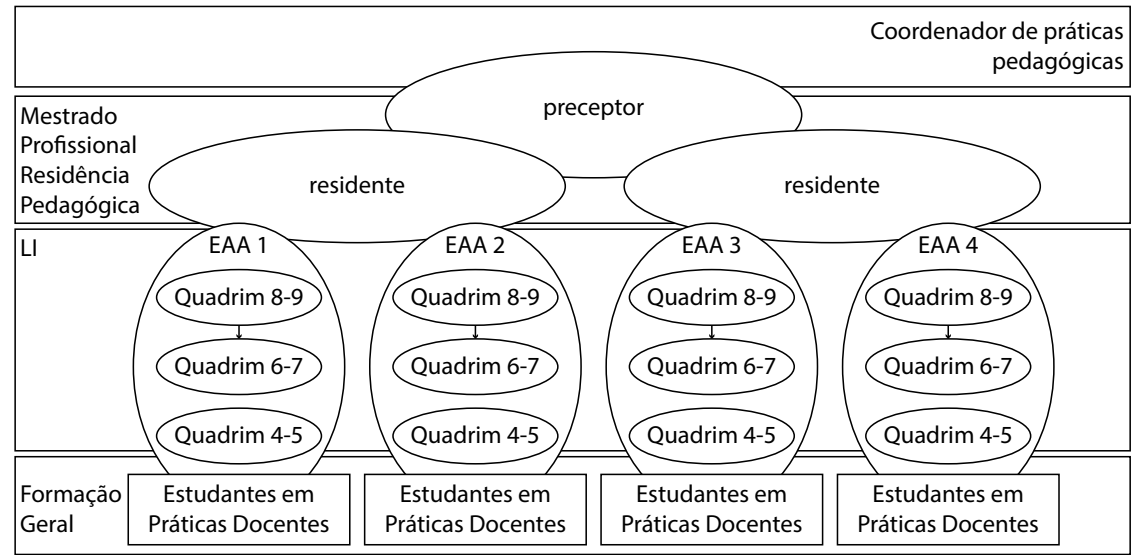

Fonte: Universidade Federal do Sul da Bahia, 2017.

LI: licenciaturas interdisciplinares; EAA: equipe de aprendizagem ativa

Nesse sistema, baseado numa estrutura de compartilhamento dos processos de ensino-aprendizagem, estudantes de diferentes turmas e coortes da LI formam equipes EAA, em que estudantes dos últimos quadrimestres são tutores de colegas do bloco intermediário que, por sua vez, cumprem o mesmo papel em relação a colegas do primeiro e do segundo quadrimestres do primeiro ano, que finalmente acolhem e orientam, em estágios rápidos, estudantes da área básica de ingresso que pretendem ingressar no curso. Cada equipe é supervisionada por pós-graduandos de residências (multiprofissionais e docentes) que recebem orientação pedagógica de preceptores docentes da rede.

Como as demais LIs da UFSB, a LI-saúde abre para o seu egresso as seguintes possibilidades: atuar como docente na educação básica; complementar estudos em um dos bacharelados interdisciplinares; seguir para o segundo ciclo (formação profissional específica); submeter-se à seleção para o terceiro ciclo (pós-graduação).

Egressos(as) da LI-saúde que postularem entrada em cursos de segundo ciclo, principalmente da área da saúde, estarão familiarizados com estratégias pedagógicas específicas para a solução de problemas de saúde e de educação inclusiva, usando as melhores evidências disponíveis, mediante processos orientados por competências, habilidades e conteúdos, em ambientes reais de ensino-aprendizagem em equipe. Em termos estritamente acadêmicos, o novo modelo proposto de educação em ciclos, orientada tecnologicamente e baseada na comunidade, com ênfase na atenção básica, responderá ao desafio 
de formar profissionais capazes de corresponder às demandas da saúde em acordo com as diretrizes curriculares nacionais, nos ambientes curriculares da rede pública de educação básica (Cardoso, Reis e Iervolino, 2008).

\section{Considerações finais}

Neste artigo, procuramos demonstrar que uma exploração simples e direta dos escritos de Anísio Teixeira permite constatar que questões essenciais da educação em saúde já estavam presentes em sua obra, nela cumprindo função estruturante. Podemos assim demarcar uma pedagogia anisiana como efeito de permanente e denodada denúncia dos modos arcaicos de ensinar, aqueles que produzem sujeitos conformados e conformistas. Vimos que, resultante desse insistente combate, encontra-se na obra anisiana permanente valorização de pedagogias críticas fundadas na capacidade de aprender fazendo. Ademais, como ainda evidenciamos, numerosos argumentos centrais do seu pensamento crítico enfatizam o papel da ciência e da tecnologia como distintivo cultural da modernidade, tanto como elemento promotor da qualidade de vida com equidade quanto como fator decisivo para a eficácia do ensino-aprendizagem.

No que se refere à arquitetura curricular, com a introdução do regime de ciclos na educação superior em saúde, buscou-se construir um modelo de educação possível e viável nesse momento crucial de revisão e recriação da universidade brasileira numa perspectiva assumidamente anisiana (Almeida-Filho, 2007). O primeiro ciclo, já implantado na UFBA e na UFSB, compõe-se de um bacharelado interdisciplinar em saúde, com duração de três anos, articulado a um modelo de integração social amplo e territorializado como a rede de colégios universitários. A entrada em licenciaturas interdisciplinares também permite mobilidade interna para os BIs, inclusive para o BI-saúde. Relata-se ainda a proposição de uma licenciatura interdisciplinar em saúde, qualidade de vida e educação inclusiva (LI-Saúde), que estava em fase preliminar de elaboração quando foi interrompido. O segundo ciclo compreende cursos e programas de formação profissional e acadêmica, destinados à habilitação de trabalhadores, gestores, pesquisadores e intelectuais em carreiras profissionais e atividades ocupacionais, em setores e áreas de atuação específicos no campo da saúde, destacando-se a formação médica.

Em relação aos processos de ensino-aprendizagem presentes na obra anisiana, recuperamos alguns elementos fundamentais do modelo da Escola Parque, especialmente temas de educação integral, inclusiva e fundada em práticas concretas. Nesse aspecto, por um lado, modelos baseados em estratégias pedagógicas ativas têm sido apresentados como eficazes para a formação de profissionais capacitados a atuar sobre os problemas concretos de saúde; modelos inovadores de aprendizagem, como o PBL (problem-based learning) e o ensino por competências, prometem focalizar a formação de profissionais nos contextos e na prática dos serviços de saúde. Por outro lado, com a constatação das limitações dos regimes convencionais de ensino ante o aporte massivo de 
novos conhecimentos científicos, enfatizam-se formatos padronizados de validação das tecnologias médicas inspirados pela epidemiologia clínica, como a EBM (evidence-based medicine) nos EUA e a colaboração Cochrane no Reino Unido, com a generalização da metanálise e dos protocolos clínicos.

Em síntese, estruturas curriculares inovadoras (num sentido radical) permitem mobilidade e mudança, com formação flexível e motivadora, mediante modelos pedagógicos ativos, baseados em problemas e centrados na autonomia do estudante, imersos na prática concreta, com modularidade progressiva (oferecendo certificações independentes a cada ciclo). Além disso, algumas dessas iniciativas têm fomentado a discussão da cultura nos currículos universitários, tornados mais abertos e participativos, numa inspiração assumidamente anisiana (Rocha, 2002).

Esperamos que a proposta de maior integração da formação profissional em saúde com os espaços tempos da docência já nos níveis básicos de educação, definidora da LI-saúde, complete seu ciclo de concepção e implantação, promovendo um novo perfil potencial de profissionais de saúde aptos a atuar numa perspectiva holística, com temas relacionados à promoção da saúde, da atividade física e da educação inclusiva no ambiente escolar. Serão sujeitos, enfim, capazes de reconhecer a complexidade social e educacional do seu território e atuar em prol da transformação da realidade, respeitando e promovendo os saberes e práticas das comunidades nas quais vivem e convivem, de forma consciente, sensível, ética e qualificada.

\section{Colaboradores}

Naomar Almeida-Filho foi responsável pela concepção, elaboração e redação final, especialmente a seção referente à Universidade Federal do Sul da Bahia; Tânia Celeste Matos Nunes contribuiu com revisão de literatura, entrevistas, elaboração da seção referente à Escola Parque e à redação final do texto.

\section{Financiamento}

Este suplemento “Educação e Trabalho em Saúde: diálogos e experiências no Brasil e em Portugal" foi realizado com apoio da Coordenação de Aperfeiçoamento de Pessoal de Nível Superior (Capes) - Código de Financiamento 001; e do Departamento de Pesquisa em História das Ciências e da Saúde da Casa de Oswaldo Cruz (Depes/COC/Fiocruz, 6151000000). Todos os autores declaram que não há conflito de interesses. 


\section{INNOVACIONES CURRICULARES PARA FORMACIÓN EN SALUD INSPIRADAS EN LA OBRA DE ANISIO TEIXEIRA}

Resumen Este artículo tuvo como objetivo compartir preguntas y reflexiones causadas por el desafío de organizar el proyecto curricular, en un régimen de ciclos, de cursos de salud en la Universidade Federal do Sul de Bahía. Inspirado por el sistema universitario estadounidense, que tiene a los colleges como el nivel inicial de educación, el primer ciclo de los cursos de salud de la institución consiste en una licenciatura interdisciplinaria de salud, con una duración de tres años, y una propuesta de capacitación docente para escuela secundaria con enfoque en la promoción de la salud, calidad de vida y educación inclusiva, aún en las etapas preliminares de preparación, lo que refuerza la integración de la universidad en el sistema educativo general. La inspiración de la obra y vida de Anísio Teixeira se revela en dos planos: en su proyecto de una universidad popular y en el concepto de escuela democrática, incorporado como un efecto práctico en el modelo de Escuela Parque, especialmente en los temas de educación integral e inclusiva fundada en prácticas concretas. Respecto a los procesos de enseñanza-aprendizaje presentes en el trabajo anisiano, el artículo destaca la apreciación de las pedagogías críticas basadas en la capacidad de 'aprender haciendo' y el papel de la ciencia y la tecnología como un distintivo cultural de la modernidad. Palabras clave: formación interdisciplinaria; escuela democrática; Anísio Teixeira; enseñanza en salud; formación en salud.

\section{Notas}

${ }^{1}$ Depois de inocentado numa comissão parlamentar de inquérito no Congresso Nacional e de responder a um inquérito policial militar, Anísio exilou-se em 1965 no Chile e nos Estados Unidos, retornando ao Brasil em tempo de participar dos movimentos em prol da reforma universitária. Faleceu em 1971, no Rio de Janeiro, em circunstâncias misteriosas que foram recentemente investigadas pela Comissão da Verdade, com fortes indícios de que sua morte teria resultado de sequestro e tortura por órgãos de repressão do regime militar.

${ }^{2} \mathrm{O}$ modelo humboldtiano define-se pela primazia da produção de conhecimento e conforma o que veio a ser chamado de 'universidade de pesquisa'. Esse modelo foi ajustado e aplicado ao contexto norte-americano no início do século XX, por meio da Reforma Flexner. O modelo bonapartista, implantado no início do século XIX, incorpora a educação superior ao sistema geral de educação, privilegiando o ensino profissional realizado em faculdades, escolas e outras unidades autônomas (Teixeira, 2005). 


\section{Referências}

ALMEIDA-FILHO, Naomar. Universidade nova: textos críticos e esperançosos. Brasília: UnB; Salvador: EdUFBA, 2007.

ALMEIDA-FILHO, Naomar. Higher education and health care in Brazil. Lancet, Londres, v. 377, n. 9.781, p. 1.898-1.900, maio 2011.

ALMEIDA-FILHO, Naomar. Nunca fomos flexnerianos: Anísio Teixeira e a educação superior em saúde no Brasil. Cadernos de Saúde Pública, Rio de Janeiro, v. 30, p. 2.531-2.553, 2014.

ALMEIDA-FILHO, Naomar; BENINCÁ, Dirceu; COUTINHO, Denise. Universidade popular e democratização de saberes: o caso da Universidade Federal do Sul da Bahia. EccoS Revista Científica, São Paulo, v. 42, p. 39-55, jan.-abr. 2017.

ALMEIDA-FILHO, Naomar et al. Formação médica na UFSB: I. Bacharelado interdisciplinar em saúde no primeiro ciclo. Revista Brasileira de Educação Médica, Brasília, v. 38, p. 337-348, 2014.

ALMEIDA-FILHO, Naomar et al. Formação médica na UFSB: II. O desafio da profissionalização no regime de ciclos. Revista Brasileira de Educação Médica, Brasília, v. 39, p. 123-134, 2015.

AROUCA, Antônio S. S. O dilema preventivista: contribuição para a compreensão e crítica da medicina preventiva. Tese (Doutorado) - Faculdade de Ciências Médicas da Universidade Estadual de Campinas, Campinas, 247p. 1975.

BRASIL. Presidência da República. Casa Civil. Subchefia para Assuntos Jurídicos. Decreto $n$. 6.286, de 5 de dezembro de 2007a. Institui o Programa Saúde na Escola - PSE, e dá outras providências. Disponível em: < http://www. planalto.gov.br/ccivil_03/_Ato2007-2010/2007/ Decreto/D6286.htm>. Acesso em: 30 set. 2019.

BRASIL. Ministério da Saúde. Escolas promotoras de saúde: experiências do Brasil. Brasília: Ministério da Saúde, Opas, 2007b. Disponível em: <http://bvsms.saude.gov.br/bvs/publicacoes/escolas_pr>. Acesso em: $28 \mathrm{dez} .2018$.
BRASIL. Ministério da Educação. Secretaria de Educação Básica. Secretaria de Educação Continuada, Alfabetização, Diversidade e Inclusão. Conselho Nacional da Educação. Diretrizes Curriculares Nacionais Gerais da Educação Básica. Brasília: Ministério da Educação, 2013. Disponível em: <http://portal. mec.gov.br/docman/julho2013-pdf/13677-diretrizes-educacao-basica2013-pdf/file $>$. Acesso em: 28 dez. 2018.

BRASIL. Ministério da Educação. Diretrizes curriculares nacionais para a Formação Inicial em Nivel Superior e para a Formação Continuada. Brasília: MEC, 2015. Disponível em: http:// portal.mec.gov.br/docman/agosto-2017-pdf/70431-res-cne-cp-002-03072015-pdf/file Acesso em: 1 out. 2019.

CARDOSO, Vanessa; REIS, Ana P; IERVOLINO, Solange A. Escolas promotoras de saúde. Journal of Human Growth and Development, v. 18, n. 2, p. 107-115. 2008. Disponível em: <http:// pepsic.bvsalud.org/scielo.php?script=sci_arttext\&pid=S0104=12822008000200001-\&lngpt\&tlng >. Acesso em: 28 dez. 2018

DONNANGELO, Maria C. Saúde e sociedade. São Paulo: Duas Cidades, 1976.

ÉBOLI, Maria T. M. Uma escola diferente. São Paulo: Companhia Editora Nacional, 1969.

FERNANDES, Marcos H.; ROCHA, Vera M.; BRASILINO DE Souza, Djanira. A concepção sobre saúde do escolar entre professores do ensino fundamental ( $1^{\mathrm{a}}$ a $4^{\mathrm{a}}$ séries). História, Ciências, Saúde: Manguinhos, Rio de Janeiro, v. 12, n. 2, p. 283-291, 2005. Disponível em: <http://www.scielo.br/scielo.php?pi$\mathrm{d}=$ S0104-59702005000200004\&script $=$ sci arttext>. Acesso em: 28 dez. 2018.

GONÇALVES, Fernanda D. et al. A promoção da saúde na educação infantil. Interface: Comunicação, Saúde, Educação, Botucatu. v. 12, n. 24, p. 181-192. 2008. Disponível em: <https:// dx.doi.org/10.1590/S1414-32832008000100014> Acesso em: 28.12.2018. 
JATOBÁ, Vandete. Entrevista sobre as bases organizativas da Escola Parque em Salvador-Bahia. Realizada por Tânia Celeste Matos Nunes em Salvador (BA), 26 jun. 2018.

MENDONÇA, Ana W. Anísio Teixeira e a universidade de educação. Rio de Janeiro: EdUERJ, 2002.

ORGANIZACIÓN PANAMERICANA DE LA SALUD. Escuelas promotoras de la salud: entornos saludables y mejor salud para las geraciones futuras. Washington, DC: OPS, 1998. (OPS Comunicación para la Salud, 13).

RIBEIRO, Darcy. A invenção da Universidade de Brasília 1961-1995. Cartas: falas, reflexões, memórias. Brasília: Imprensa do Senado Federal, 1995.

ROCHA, João A. (org.). Anísio em movimento. Brasília: Senado Federal, 2002.

SALMERON, Roberto. A universidade interrompida: Brasília 1964-1965. Brasília: EdUnB, 2008.

SILVA, Carlos S. Promoção da saúde na escola: modelos teóricos e desafios da intersetorialidade no município do Rio de Janeiro. 220f. Tese (Saúde Pública) - Escola Nacional de Saúde Pública Sergio Arouca, Fundação Oswaldo Cruz, Rio de Janeiro, 2010.
SILVA, Kenia L. et al. Promoção da saúde no Programa Saúde na Escola e a inserção da enfermagem. REME: Revista Mineira de Enfermagem, Belo Horizonte, v. 18, n. 3, p. 614-629, jul.-set. 2014.

TEIXEIRA, Anísio. Prefácio. In: Éboli, Maria T. M. Uma escola diferente. São Paulo: Companhia Editora Nacional, 1969. p.15-19.

TEIXEIRA, Anísio. Educação e universidade. Rio de Janeiro: Editora UFRJ, 1998.

TEIXEIRA, Anísio. Ensino superior no Brasil: análise e interpretação de sua evolução até 1969. Rio de Janeiro: Editora UFRJ, 2005.

UNIVERSIDADE FEDERAL DO SUL DA BAHIA (UFSB). Projeto pedagógico de curso de licenciatura interdisciplinar em saúde, atividade física e educação inclusiva. Itabuna, Porto Seguro, Teixeira de Freitas, set. 2017. Não Publicado.

VIANA FILHO, Luís. Anísio Teixeira: a polêmica da educação. São Paulo: Unesp; Salvador: EdUFBA, 2008.

VIDAL, Diana G. Escola Nova e processo educativo. In: Lopes, Eliana M. T.; Faria Filho, Luciano M. V.; VEIGA, Cynthia G. 500 anos de educação no Brasil. 2. ed. Belo Horizonte: Autêntica, 2000. p. 497-517. 